\title{
Factors Affecting the Consumption of Away-from-Home Foods in Hawai i Residents
}

\author{
Angelina M. Ahedo, Taryn W. Lee, Joan Pan, Katie M. Heinrich, Stefan Keller, Jay Maddock \\ University of Hawai i at Manoa
}

\begin{abstract}
Higher frequencies of consuming away-from-home foods has been associated with greater Body Mass Index (BMI), weight gain, and obesity, affecting people of different genders, ethnicities, and socioeconomic status (SES) groups differently. The purpose of this study was to determine how SES, ethnicity, gender, and the frequency of away-from-home food consumption at fast food and sit-down restaurants affected BMI levels and dieting practices for Hawai 1 i residents. Data were from a cross-sectional randomdigit dial telephone survey of the state of Hawai ${ }^{i}$ in the spring of 2006. Data were analyzed using a oneway ANOVA, Pearson's bivariate correlation analysis, a linear regression model, and direct logistic regression. Native Hawaiians reported eating at fast food restaurants most often (58.5\%), while Japanese participants reported eating at sit-down restaurants most often (48.6\%). Native Hawaiians had the highest rates of overweight and obesity (69.1\%), but they were most likely to report being on a diet (50.1\%), followed by Chinese participants $(49.5 \%)$. A higher frequency of eating at fast food restaurants was related to higher BMI, male gender and less education $(p<.05)$, while a higher frequency of eating at sitdown restaurants was related to higher income and more education $(p<.05)$. Higher BMI and lower income were related to dieting to lose weight $(p<.05)$. Over $6 \%$ of the variance in BMI was accounted for by gender, income, eating at fast food and sit-down restaurants, and dieting to lose weight, $F(59$, $1440)=18.63, p<.05$. The frequency of eating at fast food and sit-down restaurants as predictors for dieting to lose weight were not statistically significant $(p>.05)$. Future research should investigate what types of food are available at fast food, sit-down restaurants, or other away-from-home food sources and which types of foods at these locations consumers are more likely to select based on their SES, BMI, or dieting practices.
\end{abstract}

(C) 2007 Californian Journal of Health Promotion. All rights reserved.

Keywords: SES, BMI, Eating Out Practices, Dieting Practices

\section{Introduction}

Poor diet is one of the leading causes of death in the United States (US) and a major risk factor for obesity (Mokdad, Marks, Stroup, \& Gerberding, 2004). The direct costs associated with poor diet (in conjunction with physical inactivity) are substantial with $\$ 250$ billion spent on related medical costs every year. Indirect expenditures attributed to health conditions via poor dietary habits include employee illness and injury, absenteeism, and loss of productivity (Lin, Guthrie, \& Blaylock, 1996). Although poor diet is influenced by multiple inadequate behaviors, one probable contributor may be the consumption of away-from-home foods (Wootan \& Osborn, 2006).
Away-from-home foods, as defined by the US Department of Agriculture (USDA), include all food dispensed for immediate consumption outside of a consumer's home (Stewart, Blisard, Bhuyan, \& Nayga, 2004). More Americans consume away-from-home foods now than three decades ago (Lin, Guthrie, \& Frazao, 1999a). For example, in 2005, the average household spent $\$ 2,634$, or $\$ 1,054$ per person, on food away-from-home; and in 2007, consumers have been forecasted to spend 5\% more in restaurants (National Restaurant Association, 2007). This shift away from eating food prepared at home is partially attributable to changes in social norms. Today's fast-paced American lifestyles coincide 
with the increased availability of away-fromhome foods.

The number of fast food establishments, which tend to emphasize convenience, have increased with the greater demand for away-from-home foods (Bowman \& Vinyard, 2004). Various types of fast food restaurants exist, such as drive-thrus and take-out services. Fast food restaurants are otherwise known as "limitedservice" or "quick service" restaurants. (Sahud, Binns, Meadow, \& Tanz, 2006). There has also been an increase in full-service restaurants, defined as establishments with wait-staff. With an increasing number of individuals valuing convenience, the sales of both fast food and fullservice restaurants are rising rapidly (Stewart et al., 2004).

The quality of foods eaten outside the home has been misunderstood by many. Away-from-home foods often have a high amount of fat calories and lack many of the essential nutrients necessary for a healthy diet (Lin et al., 1996, Lin, Guthrie, \& Frazao, 1999b). Essential nutrients are more likely to be present in food prepared at home. The amount of calories contained in away-from-home foods is often high, and it is not uncommon for restaurant entrees to contain one half of the recommended calories per day at a single meal (Bowman \& Vinyard, 2004). Accordingly, studies have shown a positive association between the frequency of away-from-home food consumption and greater body mass index (BMI), weight gain, and obesity (Ma et al., 2003). However, eating more food from fast food restaurants was positively associated with higher BMI, while the same association was not true for sit-down restaurants (Duffey, GordonLarsen, Jacobs, Williams, \& Popkin, 2007). BMI has also been found to be different among gender and ethnic groups where females were more likely than males to have higher BMIs and more Blacks as compared to Whites had a higher BMI (Gallagher, Visser, Sepulveda, Pierson, Harris, \& Heysfield, 1996).

Food choices may be related to socioeconomic status (SES), where determinants of SES include income, occupation, education, ethnicity and access to resources (Freisling, Elmadfa, \& Gall, 2006). Individuals with higher formal education (i.e., college graduate or more) are more likely to understand the importance of health and healthful behaviors (Molitor, 1990), and are more likely to obtain, process, interpret, and apply knowledge that shapes nutritional or dieting practices (Mancino, Lin, \& Ballenger, 2004). Closely related to education level is income. As the number of working professionals continues to grow, increased purchases of awayfrom-home foods may be due to a combination of the factors of more discretionary income and less time for food preparation at home (Molitor, 1990).

Ethnic differences have been found for food choices, where the availability of resources for food in the neighborhood (i.e. restaurants, convenience stores, supermarkets) plays a part (Ayala, Mueller, Lopez-Madurga, Campbell, \& Elder, 2005). An analysis of the relationship between ethnicity and income with fast food availability showed that for every $10 \%$ increase in the number of fast food restaurants, neighborhood income decreased by $4.7 \%$, and the proportion of black residents increased by 3.7\% (Block, Scribner, \& DeSalvo, 2004). In 83 census tracts with at least $20 \%$ or more of the population living in poverty, neighborhoods which primarily consisted of African Americans had fewer supermarkets and more fast food restaurants (Baker, Schootman, Barnidge, \& Kelly, 2006). For a group of Latino women in Southern California, greater fast food consumption was associated with younger ages, low-wages $(<\$ 2000$ per month), and longer time of residence in the US (Ayala et al., 2005).

An additional factor that may influence food choice is dieting practices. Weight-control methods are of considerable interest to Americans as over $\$ 33$ billion is spent annually on weight-loss products and services (Kruger, Galuska, Serdula, \& Jones, 2004). In 2000 nearly half of US adults ( $46 \%$ of women and $33 \%$ of men) reported trying to lose weight, with both sexes using similar weight-loss strategies (e.g. consuming fewer calories, engaging in physical activity) (Bish, Blanck, Serdula, Marucs, Kohl, \& Khan, 2005). People with 
higher educational attainment and those who had been given medical advice to lose weight were more likely to report trying to lose weight. Despite the relationship between increased consumption of away-from-home-foods and increased BMI, it is unclear if people who report trying to lose weight by dieting choose to decrease their consumption of away-from-home foods.

While these previous studies have looked at ethnic differences for African Americans and Latina women, none have examined whether these factors apply to Hawai i residents, where the population contains a unique mixture of Asian ethnic groups and SES levels that are not found in the majority of the nation. According to the US Census Bureau (2000), 2.4\% of the nation's population reported a background with two or more races, whereas $21 \%$ of Hawai'i's population reported two or more races. Hawai'i's largest ethnic group is Asians $(41.5 \%)$, followed at a distance by White (26.8\%) (US Census Bureau, 2007). Also, Hawai $i$ has the largest Asian and Pacific Islander (API) population in the United States, accounting for $50.5 \%$ of the state's population as compared to $4.5 \%$ in the nation (US Census Bureau, 2007). Due to the unique ethnic composition and geographic isolation of the Hawaiian islands, an examination of the dietary practices and away-from-home-food consumption will provide important data for those interested in improving the health of Hawai' i's residents.

The purpose of this study was to determine how SES, ethnicity, gender, and the frequency of away-from-home food consumption at fast food and sit-down restaurants affected BMI levels and dieting practices for Hawai'i residents. Using data collected from the Spring 2006 Healthy Hawai i Initiative (HHI) cross-sectional survey, this study examined the following hypotheses: 1) higher BMIs would be predicted by a higher frequency of eating away-fromhome-food at fast-food restaurants and a lower frequency of eating away-from-home-foods at sit-down restaurants and by dieting to lose weight, with differences between ethnic groups, genders, and SES levels, and 2) those who were dieting to lose weight would be predicted by a lower frequency of consuming away-from-home foods, with differences between ethnic groups and SES levels. Different results were expected based on the type of away-from-home food consumed, either from fast food or sit-down restaurants.

\section{Method}

A cross-sectional random-digit dial telephone survey of Hawai'i residents was conducted in the spring of 2006. The survey used stratified random selection of participants in order for the sample size to be reflective of the percentage of the state's population living in each county. Verbal consent was acquired by the surveyor before the survey was conducted, and participants were thanked for their time and participation at the end of the survey. The survey was approved by the University of Hawai' $i$ at Mānoa institutional review board.

\section{Participants}

In total, there were 4,594 participants (female: $\mathrm{n}$ $=2,583,56.2 \%$; male age $=50.7, \mathrm{sd}=17.1)$ (Table 1). Participants were predominately White ( $\mathrm{n}=1,556,33.9 \%)$, followed by Japanese $(\mathrm{n}=934,20.3 \%)$, Native Hawaiians $(\mathrm{n}=793$, $17.3 \%)$, Filipinos $(\mathrm{n}=453,9.9 \%)$, Chinese $(\mathrm{n}=$ $211,4.6 \%)$, and all Other ethnicities $(n=580$, $12.6 \%$ ) with missing data on this item from $1.5 \%(n=67)$ of the sample. A large number of participants reported having college degrees $(n=$ $1,956,42.6 \%)$. Over half of the sample $(\mathrm{n}=$ $3,177,69.2 \%$ ) responded to the question on annual income, with participants predominantly earning at least $\$ 60,000(\mathrm{n}=1,604,34.9 \%)$. More participants who were Native Hawaiian reported lower annual incomes less than $\$ 20,000$ $(\mathrm{n}=126,20.9 \%)$ than all other ethnic groups. Low incomes $(<\$ 20,000)$ were also reported by $20.2 \%$ of other ethnicities and $15.3 \%$ of Chinese participants. However, Chinese participants were also the ethnic group with the largest percent of those who earned annually over $\$ 100,000(29.2 \%, \mathrm{n}=42)$. 
Table 1

Sample Demographic Characteristics $(n=4,594)$

\begin{tabular}{|l|r|r|c|}
\hline Demographic Variables & \% & Mean & SD \\
\hline Gender & & & \\
\hline Male & 43.8 & & \\
\hline Female & 56.2 & & \\
\hline Ethnicity & & & \\
\hline White & 33.9 & & \\
\hline Native Hawaiian & 17.3 & & \\
\hline Chinese & 4.6 & & \\
\hline Filipino & 9.9 & & \\
\hline Japanese & 20.3 & & \\
\hline Other & 12.6 & & \\
\hline Income & & & \\
\hline$<\$ 20,000$ & 6.2 & & \\
\hline \$20,000 - \$39,999 & 12.2 & & \\
\hline \$40,000 - \$59,999 & 15.9 & & \\
\hline \$60,000 - \$79,999 & 13.2 & & \\
\hline \$80,000 - \$99,999 & 7.1 & & \\
\hline$>\$ 100,000$ & 14.6 & & \\
\hline Education & & & \\
\hline Less than High School & 4.7 & & \\
\hline High School Graduate & 27.6 & & \\
\hline Some College & 25.2 & & \\
\hline College Graduate & 42.6 & & \\
\hline Age (years) & & 50.7 & 17.1 \\
\hline BMI & & 26.2 & 6.1 \\
\hline
\end{tabular}

\section{Survey}

The survey asked questions about demographic data and health behaviors. This study focused on a subset of the questions from the survey (including demographic factors) that asked about the frequency of eating away-from-home foods and dieting behavior. Participants were also asked how often they ate at fast food restaurants, drive-ins or lunch wagons, from hereon referred to only as fast food restaurants, and how often they ate at sit-down restaurants. The answers to these questions were based on a six point Likert scale ranging from " $6=$ almost everyday" to " 1 $=$ almost never." The survey also asked the participants if they were on a diet and whether they were dieting to lose weight and participants could respond with either "yes" or "no."

\section{Statistical Analyses}

Data were analyzed using the Statistical Package for Social Sciences (SPSS) version 15.0 (SPSS Inc., 2006). First, frequencies of eating awayfrom-home-foods at fast food and sit-down restaurants were examined by ethnicity, with the number and percent of participants reported. Next, BMI was used to determine participant weight status using National Institutes of Health (1998) standards where a BMI of $<18$ was underweight, a BMI of 18-24.9 was normal weight, a BMI of 25-29.9 was overweight, and a BMI of 30 or greater was obese. Then, frequency distributions for weight status by ethnicity and weight status by eating away-fromhome-foods at fast food or sit-down restaurants were examined. A Pearson's bivariate correlation analysis was used to further examine the relationships between BMI, the frequency of 
eating at fast food restaurants, the frequency of eating at sit-down restaurants, income, and education. A one-way ANOVA was used to examine mean differences between the different ethnic groups and the frequency of eating awayfrom-home-foods. For the first hypothesis, a linear regression model was used to predict BMI. The demographic factors of income level, education level, gender, and ethnicity were used in the first step of the model with the frequency of eating at fast food and sit-down restaurants, and dieting to lose weight in the second step of the model. In order for ethnicity to be examined in the correlation and regression model, the variable was transformed into a continuous variable with $1=$ "Yes, the participant is of the ethnicity" or $0=$ "No the participant is not of the ethnicity." All factors not meeting the criteria of $\mathrm{p}<.05$ were removed until a statistically significant model remained. For the second hypothesis, a direct logistic regression was used to predict whether or not participants were dieting to lose weight with demographic factors and the consumption of away-from-home foods at fast food and sit-down restaurants as predictors.

\section{Results}

Of all the ethnicities, Native Hawaiians were most likely to eat out at fast food restaurants with $56.5 \%(n=448)$ eating out at least every week (Table 2). As the second largest group, $55.1 \%$ of Japanese participants $(\mathrm{n}=512)$ ate out at least once a week or more at fast-food restaurants. On the opposite end of the spectrum, $29.3 \%(n=455)$ of Whites almost never ate out at fast-food restaurants. Japanese participants ate at sit-down restaurants the most frequently with $48.6 \%(n=454)$ reporting eating at sit-down restaurants at least once a week or more, followed by $47.1 \%(\mathrm{n}=100)$ of Chinese participants, and $41.4 \%(n=643)$ of Whites.

One-way ANOVA determined that there was statistically significant difference $\mathrm{F}(5,4,508)=$ $28.840, \quad \mathrm{p}<.05$ between ethnicity and the frequency of eating out at fast food restaurants. There was also a statistically significant difference $F(5,4,515)=6.269, p<.05$ between ethnicity and the frequency of eating at sit-down restaurants. Post-hoc analyses indicated that
Native Hawaiian participants ate at fast food restaurants more frequently than Chinese, Caucasian, Filipino, and Japanese participants (p $<.05)$. For sit-down restaurants, Japanese respondents ate out more frequently than both Native Hawaiian and Filipino participants while the Filipino participants ate out less frequently at sit-down restaurants than White, Chinese, and Japanese groups $(\mathrm{p}<.05)$.

More participants reported being overweight ( $\mathrm{n}$ $=1,431,33.6 \%)$ and obese $(\mathrm{n}=830,19.5 \%)$ than normal weight $(\mathrm{n}=1,866,43.8 \%)$. An examination of weight status by ethnicity showed that the largest percentage of overweight or obese participants were Native Hawaiians (34.6\%, $\mathrm{n}=257$ overweight and $34.5 \%, \mathrm{n}=256$ obese) followed by those of other ethnicities $(32.0 \%, \mathrm{n}=174$ overweight and $22.7 \%, \mathrm{n}=123$ obese), and Whites $(35.5 \%, \mathrm{n}=520$ overweight and $17.2 \%, \mathrm{n}=251$ obese). Males had higher overweight $(45.0 \%, \mathrm{n}=857)$ and obesity $(20.5 \%, \mathrm{n}=391)$ rates as compared to females $(24.5 \%, \mathrm{n}=587$ overweight and $18.5 \%, \mathrm{n}=443$ obese). Over half of obese and overweight participants reported eating at fast food restaurants once a week or more $(51.9 \%, \mathrm{n}=$ 748 and $54.7 \%, \mathrm{n}=456$, respectively) as compared to normal and underweight participants $43.6 \%(\mathrm{n}=817)$ and $28.1 \%(\mathrm{n}=$ $39), \mathrm{p}<.05$. Over $38 \%(\mathrm{n}=53)$ of underweight participants reported almost never eating at fast food restaurants; $19.4 \%$ of underweight participants reported almost never eating at sitdown restaurants.

An examination of overall dieting practices showed that $50.1 \%$ of Native Hawaiian participants $(\mathrm{n}=393), 49.5 \%$ of Chinese participants $(n=105)$ and $47.0 \%$ of Japanese participants $(n=437)$ reported being on a diet. Of those dieting, more Filipinos reported dieting to lose weight $(41.6 \%, \mathrm{n}=84)$, followed by Native Hawaiians $(41.3 \%, \mathrm{n}=161)$, and those of other ethnicities $(40.8 \%, \mathrm{n}=105)$.

Table 3 displays the results of the Pearson's bivariate correlation analysis. Statistically significant correlations were found between the frequency of eating at fast food restaurants and BMI, and education level $(\mathrm{p}<.05)$, indicating 
that those who ate more frequently at fast food restaurants tended to have higher BMIs and have lower education levels. Higher income and higher education levels were also determined to be significantly correlated with a higher frequency of eating-out at sit-down restaurants $(\mathrm{p}<.05)$. Dieting to lose weight was more likely for participants with a higher BMI and less likely for participants with higher incomes ( $p$ $<.05)$.

Table 2

Away-from-home food consumption and dieting practices by ethnicity and weight status

\begin{tabular}{|l|c|c|c|c|c|c|}
\hline Demographic Category & \multicolumn{2}{|c|}{$\begin{array}{c}\text { Ate at fast food } \\
\text { restaurants once a } \\
\text { week or more }\end{array}$} & \multicolumn{2}{|c|}{$\begin{array}{c}\text { Ate at sit-down } \\
\text { restaurants once } \\
\text { a week or more }\end{array}$} & \multicolumn{2}{|c|}{$\begin{array}{c}\text { Dieting to lose } \\
\text { weight }\end{array}$} \\
\hline & $\mathbf{n}$ & $\mathbf{\%}$ & $\mathbf{n}$ & $\mathbf{0}$ & $\mathbf{n}$ & $\%$ \\
\hline Ethnicity & & & & & & \\
\hline White & 605 & 39.0 & 643 & 41.4 & 264 & 37.5 \\
\hline Chinese & 91 & 43.7 & 100 & 47.1 & 25 & 24.0 \\
\hline Hawaiian & 448 & 56.5 & 299 & 37.7 & 161 & 41.3 \\
\hline Filipino & 225 & 49.6 & 163 & 35.9 & 84 & 41.6 \\
\hline Japanese & 512 & 55.1 & 454 & 48.6 & 120 & 27.9 \\
\hline Other & 283 & 48.8 & 213 & 36.7 & 105 & 40.8 \\
\hline BMI & & & & & & \\
\hline Underweight & 39 & 28 & 44 & 31.6 & 8 & 46.7 \\
\hline Normal & 817 & 43.6 & 797 & 42.4 & 415 & 27.5 \\
\hline Overweight & 748 & 51.9 & 599 & 41.5 & 272 & 35.6 \\
\hline Obese & 456 & 54.7 & 348 & 41.7 & 276 & 44.9 \\
\hline
\end{tabular}

Table 3

Correlations between BMI, income level, education level and the frequency of eating out and dieting to lose weight

\begin{tabular}{|l|c|c|c|c|}
\hline \multicolumn{2}{|l|}{} & BMI & Income & Education Level \\
\hline How often do you eat at fast food restaurants? & $\mathrm{r}$ & $.128^{*}$ & .025 & $-.085^{*}$ \\
& $\mathrm{~N}$ & 4351 & 3168 & 4560 \\
\hline \multirow{2}{*}{ How often do you eat at sit-down restaurants? } & $\mathrm{r}$ & -.012 & $.228^{*}$ & $.131^{*}$ \\
& $\mathrm{~N}$ & 4358 & 3173 & 4548 \\
\hline Are you dieting to lose weight? & $\mathrm{r}$ & $.140^{*}$ & $-.071^{*}$ & -.033 \\
& $\mathrm{~N}$ & 2004 & 1491 & 2106 \\
\hline
\end{tabular}

* Correlation is significant at the .05 level (2-tailed).

In the final multiple regression model, all ethnicities except for Native Hawaiians were excluded due to non-significant results. The remaining factors significantly predicted BMI, $F(7,1,438)=20.973, p<.05$ (Table 4).
Together, income, the frequency of eating at fast food and sit-down restaurants, and dieting to lose weight accounted for $9.2 \%$ of the variance in BMI. The strongest predictor of BMI was the Native Hawaiian ethnic group $(\beta=.177)$. 
Table 4

Linear Regression Predicting BMI

\begin{tabular}{|c|l|c|c|c|}
\hline Model & & $\beta$ & $t$ & Significance \\
\hline \multirow{6}{*}{2} & Gender & -.145 & -5.745 & $p<.05$ \\
\cline { 2 - 5 } & Income Level & -.100 & -3.807 & $p<.05$ \\
\cline { 2 - 5 } & Native Hawaiian & .177 & 7.004 & $p<.05$ \\
\cline { 2 - 5 } & Fast food consumption & .072 & 2.771 & $p<.05$ \\
\cline { 2 - 5 } & Sit-down restaurant consumption & -.057 & -2.107 & $p<.05$ \\
\cline { 2 - 5 } & Dieting to lose weight & -.115 & -4.566 & $p<.05$ \\
\hline
\end{tabular}

Dependent Variable: BMI continuous

Excluded Variable: Education, Ethnicity (White, Chinese, Japanese, Filipino, Other)

The direct logistic regression analysis indicated that the model with demographic variables, and the variables of eating at fast food and sit-down restaurants as predictors of dieting to lose weight against a constant-only model was not statistically significant, $\chi^{2}(5, n=4,594)=9.433$, $p>.05$. Dieting to lose weight accounted for less than $1 \%$ of the variance. The addition of the predictors did not improve the prediction success of the model.

\section{Discussion}

The primary purpose of this study was to determine how SES, ethnicity, gender, and the frequency of away-from-home food consumption at fast food and sit-down restaurants affected BMI levels and dieting practices for Hawai $i$ residents. Our results supported the first hypothesis: participants with higher BMIs ate more frequently at fast food restaurants, with differences between ethnicity and SES levels. We also found that gender, income level, of Native Hawaiian ancestry, consuming away-from-home foods, and dieting to lose weight were significant predictors of BMI.

The confirmed relationship between BMI and eating at fast food restaurants is consistent with that of previous studies. We found that participants with a higher BMI were more likely to eat at fast food restaurants, coinciding with Duffey and associates (2007) who found that fast food consumption was associated with increased BMI. Although previous research has not shown sit-down restaurant food consumption to be related to BMI (Duffey et al., 2007), we did find a significant negative relationship where a greater frequency of eating at sit-down restaurants was related to lower BMI. After controlling for gender, Native Hawaiian ancestry, and income, our data showed that eating at fast food restaurants predicted a higher BMI; however, eating at sit-down restaurants showed a protective effect $(\beta=-.057)$. Therefore, not only was a higher frequency of eating out at sit-down restaurants associated with lower BMI in the correlation, but it was also found have a protective effect against high BMI in the regression analysis. Although previous studies (Ma et al., 2003) have determined that the consumption of away-fromhome foods is associated with higher BMI, our results show that eating at sit-down restaurants is a protective factor. A possible explanation for this finding is that there may be more options to eat healthier at sit-down restaurants, as compared to fast food restaurants. Also, the ability to take home uneaten food from sit-down restaurants may discourage people from overeating.

For our second hypothesis, we were unable to confirm that those who were dieting to lose weight would be predicted by a lower frequency of away-from-home food consumption, with differences between ethnic groups and SES levels. Previous research has found that poor diet may be influenced by the consumption of away-from-home food (Wootan \& Osborn, 2006) with people who have more education attainment and those who have been given 
medical advice to lose weight being more likely to report trying to lose weight (Bish et al., 2005). According to our results, dieting to lose weight was unrelated to the consumption of away-fromhome foods from fast food and sit-down restaurants, although it was significantly related to higher BMI and lower income levels.

The determinants of SES including income, occupation, education, ethnicity and access to resources have also been found to have an effect on dietary intake that is closely related to BMI (Freisling, Elmadfa, \& Gall, 2006). In our study, we found that individuals with a higher educational level were less likely to eat at fast food restaurants but more likely to eat at sitdown restaurants, supporting previous research that individuals with higher education were more likely to obtain, process, interpret, and apply knowledge that shaped nutritional or dieting practices (Mancino et al., 2004). Although significant correlations between education and the frequency of eating out at sitdown restaurants were found, education was not a significant predictor of BMI. Income, however, was a significant predictor of BMI. We also found that individuals with higher income levels had lower BMI. Different results may have been uncovered if the study was able to measure the impact of the price of food options available at fast food or sit-down restaurants and how much one could spend on food, based on their income (Molitor, 1990).

Contrary to previous research (Gallagher et al., 1996), male participants in our study were more likely to be overweight and obese. This may be due to the ethnic composition of our sample population. According to the state of Hawai $i$ Behavioral Risk Factor Surveillance System (2006), Native Hawaiians have the highest rate of overweight $(35.8 \%, n=273)$ and obese (39.4\%, $n=306)$ among all the ethnicities in the state. Also, the BRFSS shows that there are more Native Hawaiian males $(37.9 \%, n=291)$ than females $(32.4 \%, n=370)$ who are overweight than of all the other ethnicities in Hawai i which may have affected our results. The same trend is also seen among obese Hawaiian males $(39.6 \%, n=318)$ and females $(31.3 \%, n=366)$. This shows that more research is needed on gender and BMI in Hawai $i$ in comparison to other states.

One strength of our cross-cultural study was that it addressed the limitations of previous research and examined four API subgroups, which are representative of Hawai'i's population. APIs represent $51 \%$ of the state's population (US Census Bureau, 2000). Over 99\% of the sample provided ethnicity data, allowing us to adequately examine the effects of ethnicity on eating out practices. Although ethnicity except for Native Hawaiians was not a significant predictor of the frequency of eating out at either fast food or sit-down restaurants or for dieting behavior, results indicate that there was a significant difference between ethnic groups and their eating out practices. It is important to analyze the differences between ethnic groups and away-from-home food consumption in order to examine how social norms and cultural norms affect BMI.

In today's society, the frequency of eating foods away-from-home at fast food and sit-down restaurants has increased significantly, with away-from-home foods providing between 30$42 \%$ of total daily calories (Duffey et al., 2007). The majority of our sample ate at fast food and sit-down restaurants at least once a month. Today, people favor foods that are tasty, cheap, convenient, and have nutritional value (French, 2003). Also, marketing strategies encourage consumers to eat foods that may seem healthy, but actually are not. Although our study did not specifically look at the nutritional value or the prices of the foods selected, we were, however, able to establish relationships among eating out practices between ethnic groups, SES levels, and BMI categories.

It is possible that the way the original survey was conducted may be a limitation for this study, since it was conducted by telephone and people without landlines were not able to participate in the survey. Survey questions were also only available in English; therefore the $26.6 \%$ of Hawai 1 residents who do not speak English well may have been unable to participate in the survey (U. S. Census Bureau, 2007). These residents who do not speak English 
well may be recent immigrants or elderly populations, whose participation may have changed the data and given us a better understanding of the total population of Hawai $i$. The data was collected through self-report only, intensifying the possibility of bias. Since the survey was based on self-report, it is possible that participants may have under- or overestimated their responses. The responses for the questions regarding the frequency of eating out at both fast food and sit-down restaurants required participants to remember and estimate their eating habits, which may have resulted in recall bias.

Future research should measure actual foods consumed when eating at fast food and sit-down restaurants. It is possible that the specific types of foods consumed are a confounding factor for the relationship between BMI and the frequency of eating at each type of restaurant. A measure of portion sizes would also add to the analysis. Wansink, Painter, and North (2005) have found that the visual cues provided by larger portion sizes result in the consumption of more calories, independent of BMI. Without knowing if participants were eating healthy at restaurants or were overeating, it is difficult to tell which aspect of eating at fast food or sit-down restaurants was correlated with BMI or income levels. Also, future research can examine the away-from-home food options available at the various away-from-home food sources, what participants eat, and how much they eat in order to determine possible correlations between these factors, BMI, and income levels. It is important to look at all aspects of the participant's lifestyle as well to note whether eating out practices are correlated with certain diets or physical activity levels. This study provides useful information for understanding the attitudes and behaviors of away-from-home food and dieting practices among the major ethnicities of Hawai $i$ that could translate into future development of more culturally specific interventions to improve the health of Hawai' i's residents.

\section{References}

Ayala, G. X., Mueller, K., Lopez-Madurga, E., Campbell, N. R., \& Elder, J. P. (2005). Restaurant and food shopping among Latino women in Southern California. Journal of the American Dietetic Association, 105, 38-45.

Baker, E. A., Schootman, M., Barnidge, E., \& Kelly, C. (2006). The role of race and poverty in access to foods that enable individuals to adhere to dietary guidelines. Preventing Chronic Disease: Health Research, Practice, and Policy, 3(3), 1-11.

Bish, C. L., Blanck, H. M., Serdula, M. K., Marucs, M., Kohl, H. W., \& Khan, L. K. (2005). Diet and physical activity behaviors among Americans trying to lose weight: 2000 behavioral risk factor surveillance system. Obesity Research, 13, 596-607.

Block, J. P., Scribner, R. A., \& DeSalvo, K. B. (2004). Fast food, race/ethnicity, income. American Journal of Preventive Medicine, 27, 211-217.

Bowman, S. A. \& Vinyard, B. T. (2004). Fast food consumers vs. non-fast food consumers: A comparison of their energy intakes, diet quality, and overweight status. Journal of the American College of Nutrition, 23, 163-168.

Cornelisse-Vermaat, J. R., \& van den Brink, H. M. (2007). Ethnic differences in lifestyle and overweight in the Netherlands. Obesity, 16, 483-493.

Duffey, K. J., Gordon-Larsen, P., Jacobs, D. R., Williams, O. D., \& Popkin, B. (2007). Differential associations of fast food and restaurant food consumption with 3-y change in body mass index: The coronary artery risk development in young adults study. American Journal of Clinical Nutrition, 85, 201-208.

Freisling, H., Elmadfa, I., \& Gall, I. (2006). The effect of socioeconomic status on dietary intake, physical activity, and body mass index in Austrian pregnant women. Journal of Human Nutrition Diet, 19, 437-445.

Gallagher, D., Visser, M., Sepulveda, Pierson, R. N., Harris, T., \& Heysfield, S. B. (1996). How useful is body mass index for comparison of body fatness across age, sex, and ethnic groups? American Journal of Epidemiology, 143, 228-239. 
Kruger, J., Galuska, D. A., Serdula, M. K., \& Jones, D. A. (2004). Attempting to lose weight. American Journal of Preventive Medicine, 26, 402-406.

Lin, B. H., Guthrie, J., \& Blaylock, J. R. (1996). The diets of America's children: Influence of dining out, household characteristics, and nutrition knowledge. Washington DC: U.S. Department of Agriculture, Economic Research Service, No. AER746.

Lin, B. H., Guthrie, J., \& Frazao, E. (1999a). Away-from-home foods increasingly important to quality of American diet. Washington DC: U.S. Department of Agriculture, Economic Research Service, Agricultural Bulletin No. 791.

Lin, B. H., Guthrie, J., \& Frazao, E. (1999b). Nutrient contribution of food away from home. Washington DC: U. S. Department of Agriculture, Economic Research Service, Agricultural Bulletin Number 750 .

Ma, Y., Bertone, E., Stanek, E., Reed, G. W., Hebert, J. R., Cohen, N. .L. et al. (2003). Association between eating patterns and obesity in a free-living adult population. American Journal of Epidemiology, 158, 85-92.

Mancino, L., Lin, B. H., \& Ballenger, N. (2004, October). The role of economics in eating choices and weight outcomes. Washington, DC: U. S. Department of Agriculture, Economic Research Service, Agricultural Bulletin Number 791.

Mokdad, A. H., Marks, J. S., Stroup, D. F., \& Gerberding, J. L. (2004). Actual causes of death in the United States, 2000. Journal of the American Medical Association, 291, 1238-1245.

Molitor, G. T. T. (1990). Food systems: Perspectives on demographics and affluence, food supply, and consumption. Environmental Health Perspectives, 86, 201-223.

National Institutes of Health. (1998). Clinical guidelines on the identification, evaluation, and treatment of overweight and obesity in adults: The evidence report. U. S. Department of Health and Human Services. NIH Publication No. 98-4083.

National Restaurant Association. (2007). Restaurant industry facts. Retrieved April 6, 2007, from http://www.restaurant.org/research/ind_glance.cfm

Sahud, H. B., Binns, H. J., Meadow, W. L., \& Tanz, R. R. (2005). Marketing fast food: Impact of fast food restaurants in children's hospitals. Pediatrics, 118, 2290-2297.

State of Hawai'i Department of Health. Behavioral Risk Factor Surveillance System. (2006). Body weight based on estimated BMI (Body Mass Index) status. Retrieved May 3, 2007, from http://www.hawaii.gov/health/statistics/brfss/brfss/brfss2006/2006/ demo06/bmi.html

Stewart, H., Blisard, N., Bhuyan, S., \& Nayga, R. M. (2004, January). The demand for food away from home: Full services or fast food? Washington, DC: U. S. Department of Agriculture, Economic Research Service, Agricultural Economic Report No. 829.

Thompson, O. M., Ballew, C., Resnicow, K., Must, A. Bandini, L. G., \& Dietz, W. H. (2004). Food purchased away from home as a predictor of change in BMI z-score among girls. International Journal of Obesity and Related Metabolic Disorders, 28, 282-289.

U. S. Census Bureau. (2000). The two or more races population: 2000. Retrieved April 6, 2007, from http://www.census.gov/prod/2001pubs/c2kbr01-6.pdf

U. S. Census Bureau. (2007). Hawai`i quickfacts from the U.S. Census Bureau. Retrieved April 6, 2007, from http://quickfacts.census.gov/qfd/states/15000.html

Wansink, B., Painter, J. E., \& North, J. (2003). Bottomless bowls: Why visual cues of portion size may influence intake. Obesity Research, 13, 93-100.

Wootan, M. G., \& Osborn, M. (2006). Availability of nutrition information in restaurants in the United States. American Journal of Preventive Medicine, 30, 266-268.

\section{Acknowledgments}

Funding for this study has been provided by the Hawai i Department of Health, through the Tobacco Settlement Special Fund. 
$\underline{\text { Author Information }}$

Angelina M. Ahedo, B.A

University of Hawai $i$ at Manoa

Department of Public Health Sciences

School of Medicine

1960 East West Road

Biomed D209

Honolulu, HI 96822

E-Mail: ahedo@hawaii.edu

Taryn W. Lee, M.P.H.

University of Hawai $i$ at Manoa

Department of Public Health Sciences

School of Medicine

1960 East West Road

Biomed D209

Honolulu, HI 96822

E-Mail: tarynlee@hawaii.edu

Joan Pan, M.P.H.

University of Hawai' $i$ at Manoa

Department of Public Health Sciences

School of Medicine

1960 East West Road

Biomed D209

Honolulu, HI 96822

E-Mail:.jpan@hawaii.edu

Katie M. Heinrich, Ph.D.*

University of Hawai $i$ at Manoa

Department of Public Health Sciences

School of Medicine

1960 East West Road

Biomed D104B

Honolulu, HI 96822

E-Mail: katiemh@hawaii.edu

Stefan Keller, Ph.D.

University of Hawai $i$ at Manoa

Department of Public Health Sciences

School of Medicine

1960 East West Road

Biomed D104C

Honolulu, HI 96822

E-Mail: kellers@hawaii.edu

Jay Maddock, Ph.D.

University of Hawai $i$ at Manoa

Department of Public Health Sciences 


\author{
School of Medicine \\ 1960 East West Road \\ Biomed D209 \\ Honolulu, HI 96822 \\ E-Mail: jmaddock@hawaii.edu \\ *corresponding author
}

